\title{
K-means Cluster of Personality in Predicting Self-Care Activities in Diabetes Mellitus: A Cross Sectional Study
}

\author{
Ghosh Sravanti Amiyakanti Swapna ${ }^{1}$, Debdulal Dutta Roy ${ }^{2}$ \\ ${ }^{1}$ Senior Research Fellow, \\ ${ }^{2}$ Associate Professor, \\ Psychology Research Unit, Indian Statistical Institute, Kolkata. \\ Corresponding author: Ghosh Sravant Amiyakanti Swapna \\ Email-Adhikari.sravanti@gmail.com
}

\begin{abstract}
Background: Personality traits are stable factors which can aid in understanding patient health behaviour. The five-factor model of personality can serve as a theoretical background for exploration and understanding of health behaviours. Extant studies report the implication of domains of Neuroticism and Conscientiousness in diabetes self-care behaviours. However, no study exists that take in to account a specific set of self-care behaviours in a chronic illness population and connect these to possible personality profiles. This paper presents an analysis of clustering of personality domains with relevant specific diabetes self-care behaviours, relevant demographic factors and blood glucose related outcomes in adult patients.

Methods: Self-report questionnaire data were collected from a sample of 295 patients of diabetes which included two types of diabetes (Type $1=52$; Type $2=243$ ). Tools included a measure of patient information schedule, 60-items of NEO-FFI personality inventory and Summary of Diabetes Self-care Activities (SDSCA). Following simple linear correlation, regression analysis, clustering process was initiated via Two-Step Cluster Analysis which identified two clusters as an optimal solution. Unsupervised k-means segmentation helped deduced two significantly different clusters of patients.

Results: Two clusters were found to be significantly different with respect to four domains of personality: Extraversion, Openness to Experience, Agreeableness and Conscientiousness, three critical self-care behaviours - following a general diet, following recommended diet of fruits and vegetables and performing exercise behaviour and two of the physiologic measures of blood glucose control - Fasting Blood Sugar (FBS) and Post Prandial post meal measure (PP).

Conclusion: The results show personality traits tend to cluster. This indicates that specific traits can be grouped together. In addition, specific self-care behaviours were associated with these trait combinations. Irrespective of individual factors such as age, duration of illness and gender the obtained patient profiles were distinct to one another. These findings have significant meaning for future diabetes related health programs. Findings can help in development of tailor-made intervention programs with use of such knowledge of trait clustering.
\end{abstract}

Key words: Diabetes Mellitus, Personality, Self-care behaviours, Linear Correlation, Clustering.

(Paper received $-9^{\text {th }}$ February 2018, Peer review completed $-3^{\text {rd }}$ March 2018)

(Accepted $-10^{\text {th }}$ March 2018)

\section{INTRODUCTION}

One of the central themes in health psychology is how health and illness are subject to psychological influences. There are important implications in exploring the influence of personality traits with respect to medical treatment, health education or health promotion [1-2]. Knowledge of these links allows empirical evidence-based work for different field experts involved in the health care industry. However, the causal 
link between personality and health is not always simple and linear and there could be underlying subsets and variations to this relation [3].

\section{Chronic Illness: Diabetes}

The challenges of living with any chronic illness are many. Diabetes mellitus is one such chronic illness that is on the rise in the Indian subcontinent. The data from the ICMR-INDIAB study shows that prevalence of diabetes in urban areas ranged from 10.9 to $14.2 \%$ while in rural areas the range was 3.0 to 8.3\% [4]. According to the World Health Organisation with an increase in the number of patients suffering from chronic illness such as diabetes, adherence to medication is becoming increasingly important [5]. Successful management of diabetes is dependent on performing several key self-care behaviours. Performing these key self-care behaviours is mostly the patient's responsibility. The issue with a chronic illness such as diabetes is the complex self-management nature of the illness. The performance of self-care behaviours is influenced by a variety of personal factors that affect an individual. There is growing evidence of the relation between personality traits and health behaviours [6].

\section{Importance of Personality in Health Behaviour}

Personality traits of an individual are a critical person factor that influences health behaviour. One of the major theoretical models of personality is the trait theory approach. The Oxford dictionary of psychology defines trait, as a characteristic or quality that distinguishes a person or (less commonly) a thing, especially a more or less consistent pattern of behaviour that a person possessing the characteristic would be likely to display in relevant circumstances (p.774). They form an integral part of human characteristics and can be thought of as impacting behaviour in important ways. Health behaviours then may be considered as specific manifestations of general personality traits. Findings from research on personality and health can help elucidate the mechanism through which personality impacts health [7]. For example, Axelsson and others [8] have established that a non-linear relationship may exist between certain personality traits and medicine adherence of patients with chronic illnesses. As Matthews, Deary and Whiteman [9] propose, that focussing on traits provides opportunity to study health behaviours strongly associated with different health behaviours.

\section{The Five-Factor Model (FFM) of Personality}

According to the FFM of personality the five traits that make up personality are: Neuroticism, Extraversion, Openness to Experience, Agreeableness and Conscientiousness. One of the strengths of the FFM is the brief and yet comprehensive description of personality - taxonomy it suggests. It follows the lexical approach in explanation of the structure of personality. These factors may be assumed to covary but are not interchangeable within themselves i.e they may not be assumed to overlap within each other. This comprehensive nature of the FFM allows studying personality factors as predictors as all relevant traits have been considered. Hence, if for any research study if no factor is found to be related to the criterion, it is better to abandon search for personality predictors [10]. In fact, McCrae and Costa [11], cite application of the FFM within the fields of counselling, education, forensic and health psychology. In fact, they are of the opinion that wherever, there exists any scope of personality assessment, the FFM may prove to be beneficial.

\section{Role of Personality in Diabetes Management}

Existing research work on influence of personality on diabetes management focuses on compliance to selfcare behaviors and measures of glycemic control as assessed through glycosylated hemoglobin $\left(\mathrm{HbA}_{1} \mathrm{C}\right)$ and blood sugar measures. Shamsi and others [12] found that irritable temperament was the predictor of medication compliance in type -2 diabetes patients. Certain personality characteristics deemed to be of dominating nature - being solitary, individualistic, self-centeredness with little regard for others may play a role in type - 2 DM [13]. Role of neuroticism in diabetes has been established to be of dual nature. Lane and others [14] found that neuroticism and the associated personality facets of anxiety, anger, hostility, depression, self-consciousness, and vulnerability were negatively associated with glycaemic control. Further, the patients who were high on traits of neuroticism were found to have poor blood glucose 
control. Kajanek and others [15] reported that personality profiles with high neuroticism, low agreeableness and conscientiousness had poorer adherence to a physician's recommendations. It can be assumed that certain personality profiles have a significant influence on the course of therapy and the choice of optimal therapeutic approach. Williams and others [16] found that patients high on traits of neuroticism report more symptoms that actually have no basis for underlying blood glucose levels. Owing to an enhanced neuroendocrine system, patients high on this factor are likely to experience more vague symptoms than existent. It is speculated that increased symptoms reporting is strongly related to depressive affect in patients. Owing to this the authors propose considering neuroticism as an important factor in selfassessed health, health behaviour and disease outcomes.

Lane and his team [14] propose that common personality traits may help explain variations in glycemic control achieved by patients of type-2 diabetes mellitus under conditions of standard diabetes management. Like, Jokela and others [17] concluded through a pooled analysis of cohort studies, report conscientiousness as the most important personality domain that influenced diabetes regimen. Seides [18] reports a significant inverse relationship between conscientiousness and glycosylated hemoglobin $\left(\mathrm{HbA}_{1} \mathrm{C}\right)$ for type-2 diabetes patients. This suggests that type-2 diabetes patients high on conscientious tend to be more compliant with their diabetes regimen. Some of the other related personality factors like agreeableness [18]; openness to experience, extraversion [18-19] may not always demonstrate a linear association with the relevant self-care practices.

\section{Scope of Present Study}

Existing studies on Indian diabetic patients mostly report the different personality profiles that have been observed within the patient sample $[12,20]$. The present study aims to explore whether there exists any significant difference between the two adult groups of diabetics - Type 1 and 2, with respect to personality profiles and diabetes self-care activities. It has been established through existing empirical findings that FFM domains of personality have an association with different aspects of diabetes self-care activities. There exists a scope to study personality profiles of patients. Presence of certain traits may increase or decrease the likelihood of being involved in health behaviors. The fundamental hypothesis is that certain traits underlie self-care behaviors. Any attempt at classification of patients based on common parameters has scope for creation of effective intervention programs. Such procedures can also help understand patients better and explore further possibilities for helping or treating subgroups more effectively. Clustering can serve as an effective and useful analytic technique in health psychology as means of addressing theoretical and practical problems. Cardiac disorders/hypertension, pain and cancer are some of the illness groups that have been studied through means of cluster analysis extensively [21]. Much of the personality studies within the Indian context are limited to exploration of small groups of patients. Few if any have considered adult Type-1 patients. Identifying these gaps, the present authors considered working with patients of two groups of diabetes groups - Type 1 and Type 2 .

\section{METHODOLOGY}

\section{Participants}

A cross-sectional survey design was utilized to gather primary data. A total of 310 patients of diabetes were approached but only 295 patients provided their consent for the study. Written consent was obtained from each of the patients, following the Indian Council of Medical Research (ICMR) guidelines. The present sample consisted of patients of both Type-1 $(n=52)$ and Type- $2(n=243)$ diabetes (Table 1$)$. They were randomly selected from the diabetes and endocrine outpatient department (OPD) of the Institute of Post-Graduate Medical Education and Research (IPGMER) and SSKM Hospital in Kolkata, India. Patient inclusion criteria included diagnosis of at least 3 months with type 1 or type 2 diabetes, a minimum educational level of grade 4 and ability to read and comprehend survey materials, age between 18-50 years, written individual patient consent following Indian Council of Medical Research (ICMR) regulations and patients who perform activities of daily living independently. Exclusion criteria included patients with previous history of psychiatric illness, any surgery within the last three months, patient's dependent on others to perform self-care activities and women patients with gestational diabetes. 
Survey forms were administered individually to each participant by the principal investigator of the study. In this sample, $17.62 \%(n=52)$ constituted Type 1 patients as compared to $82.37 \%(n=243)$ representation of Type 2 patients. One explanation for smaller percentage representation of Type 1 patients is incidence of $\mathrm{T}_{1} \mathrm{DM}$ is $5-10 \%$ in population of all diabetes mellitus cases [22]. Following the modified Kuppuswamy Socio-Economic Classification [23] patients were classified into different socio-economic groups.

\section{Measures}

A Patient Information Schedule: It included items to obtain patient information of gender, age, duration of diabetes, educational status, marital status, employment status, any existing co-morbid conditions of the patient and measures of height, weight and BMI.

The NEO Five - Factor Inventory - 3 (NEO-FFI-3): Developed by Costa and McCrae [11] was used. The inventory consists of 60 items across the five domains of Neuroticism (N), Extraversion (E), Openness to Experience (O), Agreeableness (A) \& Conscientiousness (C). The respondent has to respond to the statements (12 per domain) through a 5- point Likert rating scale, that ranges from Strongly disagree (SD) to Strongly Agree (SA). The sample items included, "I am not a worrier".

Summary of Diabetes Self-care Activities (SDSCA): Developed by Toobert, Hampson and Glasgow [24] it is a self-reported measure of diabetes self-care activities, made up of 11 core items that assesses patient's response to different self-care activities of- Diet, Exercise, Blood glucose testing, Foot care and Smoking for the past seven days. Sample items included, "How many of the last seven days have you followed a healthful eating plan?". The response scale ranged from 0 days to 7 days. Good self-care behaviours were defined as follows - In the diet component of the SDSCA, general diet and specific diet of fruits and vegetable intake of five days or more in the last seven days, specific diet of red meat and fats consumption for one day in the past seven days, in the exercise component, exercising for at least 30 minutes a day for five days or more for the last seven days, monitoring blood glucose levels at least once in the past one month.

\section{Data Collection Procedures}

Initially, approval of the plan of work was sought by the ethics committee of the Indian Statistical Institute, Kolkata and the Institute of Post-Graduate Medical Education and Research (IPGMER), Kolkata. A working translation of the survey tools was done in the regional language, Bengali. This was done adhering to the ICMR regulations. It was language of majority of the patients. This eased the process of data collection. Hence, prior to data collection, each of the measure was forward and backward translated from English to Bengali with assistance from the Linguistic Research Unit, Indian Statistical Institute, Kolkata. Patients were randomly sampled from the tickets collected of those visiting the OPD for the day. Each of the patient was briefed about the objectives of the study and their role in it. After obtaining written informed consent, data was individually collected from each of the patients. Information about the measures of blood sugar was collected from the patient's recent test reports. Post data collection, the patients were thanked for their participation. Statistical analysis of the data was done using IBM-SPSS (Version 20) software.

\section{STATISTICAL ANALYSIS}

Although this was an exploratory investigation, one of the main aims was to study linear associations between the different personality domains and self-care activities. To limit the overall number of statistical tests, the analysis proceeded in three stages. First, linear associations were explored for each NEO-FFI-3 personality domain with self-care activities. Significant correlations were identified with subset of self-care activities. Second stage was to explore whether patients of the two groups of diabetes- Type 1 and Type 2 differed with respect to the NEO-FFI-3 domains of personality and diabetes self-care behaviours. Third stage involved reanalysing the profile of patients with respect to personality domains. Present data has been collected from patients coming from different demographic backgrounds (Table 1). This may be assumed to influence the patient profile with respect to NEO-FFI-3 personality domains. To further explore whether the existing patient sample arises from multiple populations in terms of personality traits, 
unsupervised segmentation using Cluster Analysis was performed. This procedure would help to find natural grouping of clusters within the patient sample with respect to their personality profiles.

\section{RESULTS}

In present sample of 295 patients with diabetes, representation of male patients in total sample was $64.06 \%$ and females was $36.27 \%$. The average age (in years) of Type 1 patients was 25.04 years $(S . D=9.60)$ and for Type 2 patients was 40.29 years $(S . D=7.16)$. There was a significant difference in age of patients (in years) between the two groups of diabetes, $\mathrm{t}(293)=-11.50, \mathrm{p}<0.001$, with Type 2 patients being significantly older in ages than patients with Type 1 diabetes. Likewise, the duration of illness for Type 1 patients (in months) was $80.33(\mathrm{~S} . \mathrm{D}=60.60)$ and for Type 2 patients was 64.26 months $(\mathrm{S} . \mathrm{D}=56.55)$. Maximum patient representation was observed of patients from the upper-lower socio-economic status (42.71\%). Significant differences were observed in the percentage of patients from different demographic classification, $\chi 2(4, \mathrm{~N}=295)=33.28, \mathrm{p}=0.0001$. (Table 1$)$.

It was observed that patients with Type 1 diabetes showed greater variability for measures of blood sugar such as $\mathrm{HbA}_{1} \mathrm{C}$ (in \%) (Mean= 8.96, S.D = 2.40) as compared to patients with Type 2 diabetes (Mean= 8.35, S.D = 2.10). Similar trend was observed for fasting blood sugar in Type 1 patients (Mean $=152.25$, S.D $=87.07)$ as compared to Type 2 patients $(M e a n=156.87$, S.D $=75.74)$. The average post prandial measure, which is the report of blood sugar level post two hours of a meal for type 1 patients was 208.23 $(\mathrm{mg} / \mathrm{dl})(\mathrm{S} . \mathrm{D}=158.36)$ compared to the average of patients with Type 2 diabetes $222.51(\mathrm{mg} / \mathrm{dl}),(\mathrm{S} . \mathrm{D}=$ 104.94). There were significant mean differences in the post prandial measure of blood sugar between the patients of Type 1 and Type 2 diabetes, $t(293)=-0.63, p<0.01$.

Table 1 - Participant Characteristics

\begin{tabular}{|c|c|c|c|c|}
\hline $\begin{array}{c}\text { Patient } \\
\text { Characteristics }\end{array}$ & Type 1 & Type 2 & Total & $\begin{array}{c}x^{2} \text { or } \\
t \text { - test }\end{array}$ \\
\hline $\mathbf{N}$ & 52 & 243 & 295 & \\
\hline Sex & $\begin{array}{c}\text { Male }=33 \\
\text { Female }=19\end{array}$ & $\begin{array}{l}\text { Male }=156 \\
\text { Female }=87\end{array}$ & $\begin{array}{c}\text { Male }=189(64.06 \%) \\
\text { Female }=107(36.27 \%)\end{array}$ & \\
\hline Age (in years) & $\begin{array}{l}\text { (M) } 25.04 \\
\text { (SD) } 8.84\end{array}$ & $\begin{array}{l}\text { (M) } 40.09 \\
\text { (SD) } 7.16\end{array}$ & $\begin{array}{l}\text { (M) } 37.44 \\
\text { (SD) } 9.42\end{array}$ & $-11.50 * *$ \\
\hline \multicolumn{4}{|c|}{ Kuppuswamy Socio-economic Status (SES) } & \multirow{6}{*}{$33.28^{* *}$} \\
\hline Lower (n) & 4 & 0 & 10 & \\
\hline Upper Lower & 34 & 98 & 132 & \\
\hline Middle & 9 & 90 & 99 & \\
\hline Upper Middle & 5 & 54 & 59 & \\
\hline Upper & 0 & 1 & 01 & \\
\hline $\begin{array}{c}\text { Duration of } \\
\text { Diabetes }\end{array}$ & $\begin{array}{l}\text { (M) } 80.33 \\
\text { (SD) } 60.60\end{array}$ & $\begin{array}{l}\text { (M) } 64.26 \\
\text { (SD) } 56.55\end{array}$ & $\begin{array}{l}\text { (M) } 67.11 \\
\text { (SD) } 57.51\end{array}$ & 0.17 \\
\hline $\begin{array}{l}\text { Presence of more } \\
>1 \text { complication }\end{array}$ & $\begin{array}{c}15 \\
28.84 \%\end{array}$ & $\begin{array}{c}15 \\
6.17 \%\end{array}$ & $\begin{array}{c}30 \\
0.10 \%\end{array}$ & - \\
\hline $\mathrm{HbA}_{1} \mathrm{C}(\%)$ & $\begin{array}{c}\text { (M) } 8.96 \\
\text { (SD) } 2.40\end{array}$ & $\begin{array}{l}\text { (M) } 8.35 \\
\text { (SD) } 2.10\end{array}$ & $\begin{array}{l}\text { (M) } 8.44 \\
\text { (SD) } 2.15\end{array}$ & 1.23 \\
\hline $\begin{array}{l}\text { Fasting Blood } \\
\text { Sugar }\end{array}$ & $\begin{array}{l}\text { (M) } 152.25 \\
\text { (SD) } 87.07\end{array}$ & $\begin{array}{l}\text { (M)156.87 } \\
\text { (SD) } 75.74\end{array}$ & $\begin{array}{l}\text { (M)156.06 } \\
\text { (SD) } 77.71\end{array}$ & $\begin{array}{l}-0.34 \\
\end{array}$ \\
\hline $\begin{array}{l}\text { Post Prandial } \\
\text { Blood Sugar }\end{array}$ & $\begin{array}{l}\text { (M) } 208.23 \\
\text { (SD) } 158.36\end{array}$ & $\begin{array}{l}\text { (M) } 222.51 \\
\text { (SD) } 104.94\end{array}$ & $\begin{array}{l}\text { (M) } 219.94 \\
\text { (SD) } 113.77\end{array}$ & $-0.63^{*}$ \\
\hline
\end{tabular}

Self-care activities as assessed through the Summary of Diabetes Self - Care Activities (SDSCA) indicated the highest percentage, $19.8 \%$ of the sample followed the recommendations of general diet for at least four days in the past week, followed by $23.6 \%$ for the specific diet recommendations of fruits and vegetables, followed by $29.4 \%$ who consumed red meats and fats and full fat dairy products for only one day in the 
last seven days, the highest percentage, $25.2 \%$ failed to exercise for even a day in the past seven days, while $61 \%$ checked their blood glucose levels at least once in the past one month (Table 2).

Table 2 - Individual responses to the Summary of Diabetes Self-Care Activities (SDSCA) and frequency of each response $(\mathrm{N}=295)$

\begin{tabular}{|c|c|}
\hline Summary of Diabetes Self-Care Activities Items & n (\%) \\
\hline \multicolumn{2}{|c|}{$\begin{array}{l}\text { General Diet } \\
\text { On how many of the last seven days have you followed a healthful eating plan? }\end{array}$} \\
\hline \multicolumn{2}{|c|}{\begin{tabular}{|c|c|} 
Number of Days of Week &
\end{tabular}} \\
\hline 0 & $23(7.3 \%)$ \\
\hline 1 & $30(9.6 \%)$ \\
\hline 2 & $45(14.4 \%)$ \\
\hline 3 & $23(7.3 \%)$ \\
\hline 4 & $62(19.8 \%)$ \\
\hline 5 & $31(9.9 \%)$ \\
\hline 6 & $51(16.3 \%)$ \\
\hline 7 & $30(9.6 \%)$ \\
\hline \multicolumn{2}{|l|}{ Specific Diet- Fruits and Vegetables: } \\
\hline \multicolumn{2}{|c|}{ On how many of the last seven days did you eat 5 or more servings of fruits and vegetable } \\
\hline $\begin{array}{cc} & 0\end{array}$ & $6(1.9 \%)$ \\
\hline 1 & $9(2.9 \%)$ \\
\hline 2 & $33(10.5 \%)$ \\
\hline 3 & $33(10.5 \%)$ \\
\hline 4 & $49(15.7 \%)$ \\
\hline 5 & $57(18.2 \%)$ \\
\hline 6 & $34(10.9 \%)$ \\
\hline 7 & $74(23.6 \%)$ \\
\hline \multicolumn{2}{|l|}{ Specific Diet - Red meats and Fat } \\
\hline \multicolumn{2}{|c|}{$\begin{array}{l}\text { How many of the last } 7 \text { days did you eat high fat foods as red meat or full-fat dairy } \\
\text { products }\end{array}$} \\
\hline 0 & $91(29.1 \%)$ \\
\hline 1 & $92(29.4 \%)$ \\
\hline 2 & $49(15.7 \%)$ \\
\hline 3 & $24(7.7 \%)$ \\
\hline 4 & $14(4.5 \%)$ \\
\hline 5 & $10(3.2 \%)$ \\
\hline 6 & $5(1.6 \%)$ \\
\hline 7 & $10(3.2 \%)$ \\
\hline \multicolumn{2}{|c|}{ Exercise Behaviour } \\
\hline 0 & $79(25.2 \%)$ \\
\hline 1 & $21(6.7 \%)$ \\
\hline 2 & $24(7.7 \%)$ \\
\hline 3 & $21(6.7 \%)$ \\
\hline 4 & $34(10.9 \%)$ \\
\hline 5 & $31(9.9 \%)$ \\
\hline 6 & $23(7.3 \%)$ \\
\hline 7 & $62(19.8 \%)$ \\
\hline
\end{tabular}




\begin{tabular}{|c|c|}
\hline \multicolumn{3}{|c|}{ Blood Glucose Testing: } \\
\hline On how many days the last month did you test your blood sugar? \\
\hline 0 & $27(8.6 \%)$ \\
\hline 1 & $\mathbf{1 9 1 ( 6 1 . 0 \% )}$ \\
\hline 2 & $45(14.4 \%)$ \\
\hline 3 & $7(2.2 \%)$ \\
\hline 4 & $8(2.6 \%)$ \\
\hline 5 & $1(0.3 \%)$ \\
\hline 6 & $8(2.6 \%)$ \\
\hline 7 & $8(2.6 \%)$ \\
\hline
\end{tabular}

\section{Correlational Analysis: Participant Characteristics, Personality and Diabetes Self-Care Activities}

Point biserial $\left(\mathrm{r}_{\mathrm{pb}}\right)$ is a special case of linear correlation when one of the variable is categorical and the other continuous (Nunnally \& Bernstein, p. 125). No significant association was obtained between the participant characteristic of gender, socio-economic status, domains of personality and self-care activities. However, significant association between age of participant and personality domain of Conscientiousness $(\mathrm{r}=0.12, \mathrm{p}=0.03)$ and between socio-economic status score (SES) and self-care activity of exercise behavior $(\mathrm{r}=0.15, \mathrm{p}=0.008)$ was observed.

\section{Correlational Analysis: Personality and Diabetes Self-Care Activities}

Simple linear association between personality and self-care activity of the diabetic patients $(\mathrm{N}=295)$ revealed that four of the five factors of the FFM personality - Neuroticism, Extraversion, Openness to experience and Conscientiousness were implicated in different diabetes self-care activities (Table 3). Significant negative association of Neuroticism was found with three of the self-care behaviors. While, significant positive association was observed between domains of Extraversion, Openness to Experience and Conscientiousness with three of the self-care activities (Table 3).

Neuroticism: The Pearson correlation between the overall Neuroticism domain and the general diet variable was significant and negative with self-care behaviours of following general diet $(r=-0.13, p=0.05)$. The correlations between Neuroticism and specific diet of fruits and vegetables diet was significant and negative with self-care behaviours $(\mathrm{r}=-0.13, \mathrm{p}=0.05)$ and exercise behaviour $(\mathrm{r}=-0.17, \mathrm{p}=0.01)$.

Extraversion: The Pearson correlation between the overall Extraversion domain and the general diet variable was significant and positive with self-care behaviours of following general diet $(r=0.14, p=0.05)$, significant and positive with specific diet of fruits and vegetables diet $(\mathrm{r}=0.13, \mathrm{p}=0.05)$ and exercise behaviour ( $\mathrm{r}=-0.17, \mathrm{p}=0.01)$.

Openness to Experience: The Pearson correlation between the overall Openness to Experience domain and self-care behaviours of specific diet of fruits and vegetables diet $(r=0.13, p=0.05)$ and exercise behaviour $(\mathrm{r}=-0.16, \mathrm{p}=0.01)$ was significant and positive.

Conscientiousness: The Pearson correlation between the overall Conscientiousness domain and self-care behaviours of general diet $(r=0.14, p=0.05)$ and exercise behaviour $(r=0.24, p=0.01)$ was significant and positive.

\section{Step-Wise Regression Analysis: Predicting Self-Care Behaviors}

Stepwise regression analysis was conducted to determine the extent to which the personality domains could predict the different self-care behaviors (Table 4). Results indicated that only the personality domain of Conscientiousness was significant $(\beta=0.05, \mathrm{p}<0.01)$ and explained $2.2 \%$ of the variance $\left(\mathrm{R}^{2}=0.02, \mathrm{~F}\right.$ $(1,293)=6.61, p=0.01)$ in prediction of the self-care behavior of following the general diet. In predicting self-care behavior of consuming fruits and vegetables, only the domain of Extraversion was significant ( $\beta=$ $0.04, \mathrm{p}<0.01)$ and explained $1.9 \%$ of the variance $\left(\mathrm{R}^{2}=0.19, \mathrm{~F}(1,293)=5.69, \mathrm{p}=0.01\right)$. In predicting self-care behavior of performing exercise, two personality domains explained $7.4 \%$ of the variance $\left(\mathrm{R}^{2}=\right.$ $0.074, \mathrm{~F}(1,292)=11.69, \mathrm{p}=0.0001)$. It was found that Conscientiousness $(\beta=0.10, \mathrm{p}<0.0001)$ and domain 
of Neuroticism $(\beta=0.04, p<0.0001)$ significantly predicted self-care behavior of performing exercise behavior.

Table 3 - Simple Linear Correlations between Personality Domains of FFI-3 and Diabetes Self-care Activities $(\mathrm{N}=295)$

\begin{tabular}{|c|c|c|c|c|c|}
\hline \multicolumn{2}{|c|}{} & \multicolumn{3}{|c|}{ Diabetes Self-Care Activities (DSCA) } \\
\cline { 3 - 6 } \multicolumn{2}{|c|}{} & General Diet & Vegetable Diet & $\begin{array}{c}\text { Red Meat \& } \\
\text { Fats Diet }\end{array}$ & Exercise \\
\hline $\begin{array}{c}\text { Personality } \\
\text { Domains }\end{array}$ & Neuroticism & $\mathbf{- 0 . 1 3}^{*}$ & $\mathbf{- 0 . 1 3}^{*}$ & 0.05 & $\mathbf{- 0 . 1 7}^{* *}$ \\
\cline { 2 - 6 } & Extraversion & $\mathbf{0 . 1 4}$ & $\mathbf{0 . 1 3}$ & -0.08 & $\mathbf{0 . 1 7}^{* *}$ \\
\cline { 2 - 6 } & $\begin{array}{c}\text { Openness to } \\
\text { Experience }\end{array}$ & 0.01 & $\mathbf{0 . 1 3}^{*}$ & -0.09 & $\mathbf{0 . 1 6}^{* *}$ \\
\cline { 2 - 6 } & Agreeableness & 0.09 & -0.02 & -0.05 & -0.01 \\
\cline { 2 - 6 } & Conscientiousness & $\mathbf{0 . 1 4}$ & 0.02 & -0.07 & $\mathbf{0 . 2 4}^{* *}$ \\
\hline
\end{tabular}

** Correlation is significant at the 0.01 level (2-tailed)

* Correlation is significant at the 0.05 level (2-tailed)

Table 4 - Results of the Step-wise Multiple Regression Analysis of Personality domains in predicting diabetes self-care behaviors $(\mathrm{N}=295)$

\begin{tabular}{|c|c|c|c|c|c|c|}
\hline Model & Variables & B & $\mathrm{R}^{2}$ & $\mathrm{df}_{1}, \mathrm{df}_{2}$ & $F$ & Sig. \\
\hline \multicolumn{7}{|c|}{ General Diet } \\
\hline 1 & Conscientiousness & 0.055 & 0.022 & 1,293 & 6.61 & 0.01 \\
\hline \multicolumn{7}{|c|}{ Special Diet- Fruits and Vegetables } \\
\hline 1 & Extraversion & 0.044 & 0.019 & 1,293 & 5.69 & 0.01 \\
\hline \multicolumn{7}{|c|}{ Exercise } \\
\hline 1 & Conscientiousness & 0.115 & 0.060 & 1,293 & 18.73 & 0.0001 \\
\hline 2 & $\begin{array}{l}\text { Conscientiousness } \\
\text { Neuroticism }\end{array}$ & $\begin{array}{l}0.101 \\
-0.046\end{array}$ & 0.074 & 1,292 & 11.69 & 0.0001 \\
\hline
\end{tabular}

\section{Comparison of Means: Personality, Diabetes Self-Care Activities and Type of Diabetes}

A t-test was conducted to test whether patients of Type 1 and Type 2 diabetes differ with respect to variables of personality and diabetes self-care activities (Table 5). No significant differences were observed between the two groups with respect to any of the domains of personality. However, the two groups of patients were found to differ significantly with respect to self-care activity of blood glucose testing. This finding is in the expected direction as patients with Type 1 diabetes are usually expected to test their blood glucose nearly six times a day. While patients with Type 2 diabetes are recommended maybe once or twice a month, depending on their treatment plan by the physician.

\section{Clustering of Personality Traits}

Significant differences have been established from patients coming from different socio-economic and demographic backgrounds (Table 1). It could be assumed that owing to the wide variability in the background of patients in the present sample, it would produce an influence on the personality profile of the patients. The objective was to explore whether the patients could be classified in a sound statistical manner, which would also be theoretically meaningful. For this purpose, a k-means cluster analysis was done. Cluster analysis is a multivariate technique which can help identify homogeneous sub-types within a complex data set. Clustering algorithms can be used to search a data set to help partition objects (or people) into relatively distinct groups [25]. It helps in data reduction and interpretation when we are interested to look for patterns that group together several cases. Individual patient observation of 
personality scores as obtained on the NEO-FFI 3 were utilized. Obtained results revealed two distinct clusters of patients as an optimal solution (Fig.1).

To determine the statistical significance of the obtained clusters, Kolmogorov-Smirnov Z test was computed. This is a non-parametric test that does not assume that data are sampled from Gaussian or any defined distributions. Obtained results indicated that the patients were sampled from populations with different distributions. This helps us determine that probability of two cumulative frequency distributions are as far apart as observed. It was observed that in cluster 2 the scores on the other three domains of personality of NEO-FFI-3 and the self-care activities- General diet, Specific Diet- vegetable and fruits, Specific Diet - red meat and fats, and Exercise behaviour are comparatively lower than that of cluster 1 (Table.4). It was observed that cluster 2 has grouping of patients with high scores on Neuroticism $(\mathrm{M}=39.76, \mathrm{~S} . \mathrm{D}=7.04)$ and Conscientiousness $(\mathrm{M}=44.46, \mathrm{~S} . \mathrm{D}=5.87)$, as compared to scores of patients of cluster $1(\mathrm{M}=37.08, \mathrm{~S} . \mathrm{D}=7.07)$ and $(\mathrm{M}=43.56$, S.D $=4.93)$ respectively (Fig.2). Further, in comparing the profile of self-care activities across the clusters, it can be seen that Cluster 1 has patients who possessed higher averages in all of the self-care activities except specific diet of red meat and fats (Fig.3). A comparison of physiological measures of blood glucose levels across the clusters indicates significant difference in measures of fasting blood sugar and post meal (post prandial measure). Patients with low scores on these parameters were found to belong to Cluster 1 as compared to Cluster 2 .

Table 5 - Comparison of Means of variables of Personality and Self-care activities between the two types of diabetes groups, Type $1(n=52)$ and Type $2(n=243)$.

\begin{tabular}{|c|c|c|c|c|c|c|}
\hline & Variable & $\mathbf{N}$ & Mean & S. D & $t$ & p-value \\
\hline \multirow{5}{*}{$\begin{array}{l}\text { Personality } \\
\text { Domains } \\
\text { (NEO-FFI-3) }\end{array}$} & Neuroticism & \multirow{10}{*}{$\begin{array}{c}T_{1}=52 \\
T_{2}=243\end{array}$} & $\begin{array}{l}27.37 \\
27.39\end{array}$ & $\begin{array}{l}8.07 \\
7.13\end{array}$ & -0.12 & 0.89 \\
\hline & Extraversion & & $\begin{array}{l}28.54 \\
28.47\end{array}$ & $\begin{array}{l}5.49 \\
6.21\end{array}$ & -0.10 & 0.92 \\
\hline & Openness to Experience & & $\begin{array}{l}30.13 \\
28.67\end{array}$ & $\begin{array}{l}5.36 \\
5.57 \\
\end{array}$ & 1.61 & 0.122 \\
\hline & Agreeableness & & $\begin{array}{l}28.60 \\
27.63\end{array}$ & $\begin{array}{l}4.96 \\
5.24\end{array}$ & 1.08 & 0.303 \\
\hline & Conscientiousness & & $\begin{array}{l}32.02 \\
33.07\end{array}$ & $\begin{array}{l}5.07 \\
5.95\end{array}$ & -1.53 & 0.171 \\
\hline \multirow{5}{*}{$\begin{array}{c}\text { Diabetes } \\
\text { Self-care Activities }\end{array}$} & General Diet & & $\begin{array}{l}3.83 \\
3.74 \\
\end{array}$ & $\begin{array}{l}1.96 \\
2.16\end{array}$ & 0.28 & 0.791 \\
\hline & Vegetable Diet & & $\begin{array}{l}5.02 \\
4.59 \\
\end{array}$ & $\begin{array}{l}1.93 \\
1.89 \\
\end{array}$ & 1.44 & 0.143 \\
\hline & Red Meat and Fats Diet & & $\begin{array}{l}1.61 \\
1.78 \\
\end{array}$ & $\begin{array}{l}1.56 \\
1.59 \\
\end{array}$ & -0.13 & 0.897 \\
\hline & Exercise & & $\begin{array}{l}3.79 \\
3.28 \\
\end{array}$ & $\begin{array}{l}2.65 \\
2.70\end{array}$ & 1.24 & 0.221 \\
\hline & Blood Glucose Testing & & $\begin{array}{l}2.60 \\
1.27 \\
\end{array}$ & $\begin{array}{l}2.10 \\
1.11 \\
\end{array}$ & 4.41 & 0.0001 \\
\hline
\end{tabular}

Figure 1 - Cluster Profiles as obtained by 2 step cluster analysis

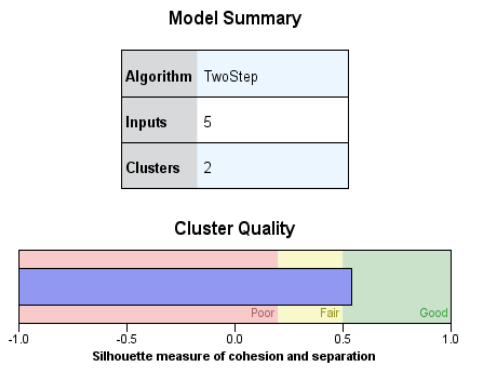


Figure 2 - Graphical Representation of Personality Domains across the 2 clusters

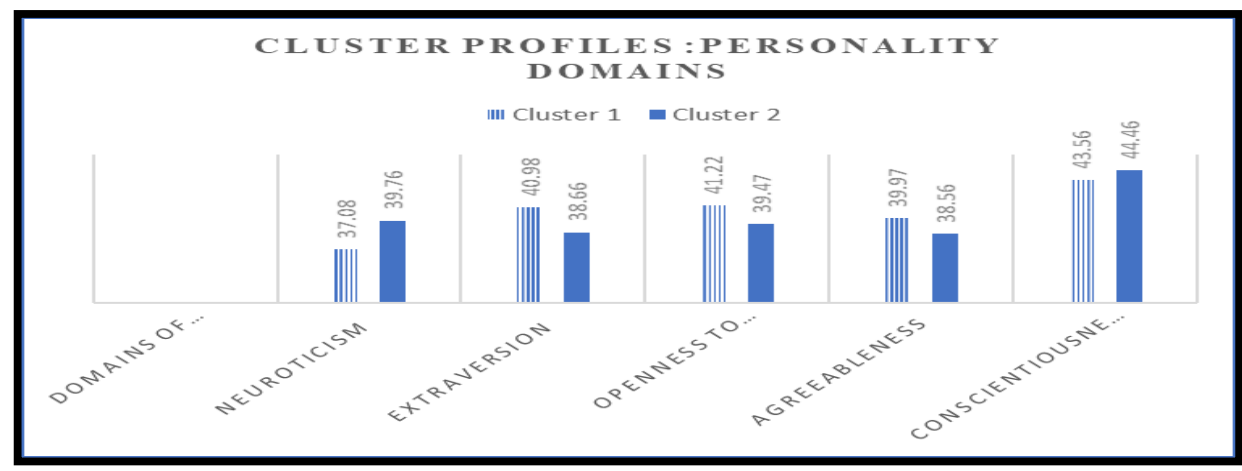

Figure 3 - Graphical Representation of Self Care across the 2 clusters

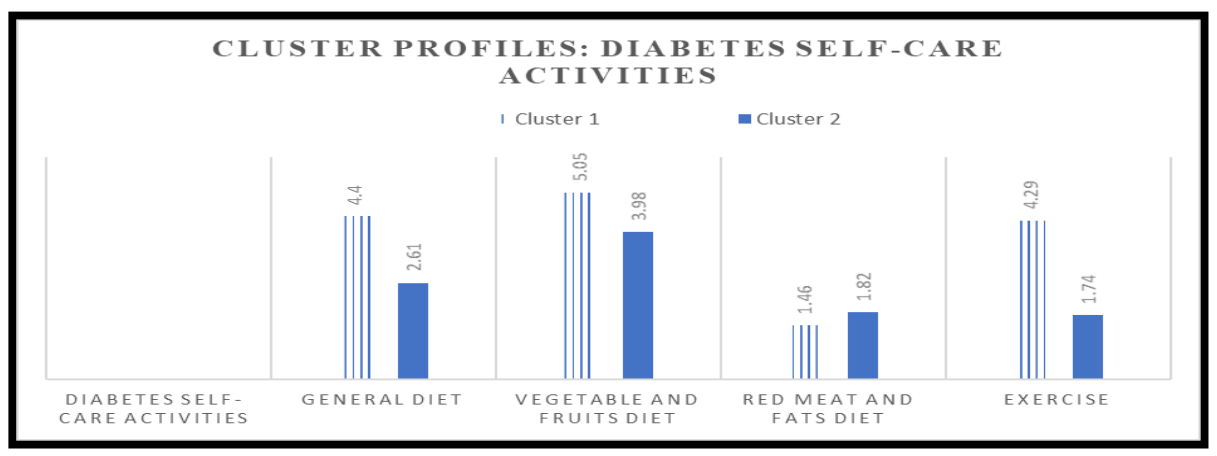

Table 6 - Details of the Cluster profiles

\begin{tabular}{|c|c|c|c|c|c|}
\hline \multirow[t]{2}{*}{ Variables } & \multicolumn{2}{|c|}{$\begin{array}{l}\text { Cluster } 1 \\
(n=189)\end{array}$} & \multicolumn{2}{|c|}{$\begin{array}{l}\text { Cluster } 2 \\
(n=106)\end{array}$} & \multirow[b]{2}{*}{ Sig. level } \\
\hline & Mean & S.D & Mean & S.D & \\
\hline \multicolumn{6}{|c|}{ Demographic Variables } \\
\hline Age (in years) & 37.88 & 9.41 & 36.63 & 9.43 & 0.20 \\
\hline Duration in illness (in months) & 69.16 & 74.60 & 70.13 & 57.73 & 0.70 \\
\hline \multicolumn{6}{|c|}{ Personality Variables } \\
\hline Neuroticism & 37.08 & 7.07 & 39.76 & 7.04 & 0.105 \\
\hline Extraversion & 40.98 & 5.67 & 38.66 & 6.10 & $0.022^{* *}$ \\
\hline Openness to Experience & 41.22 & 5.54 & 39.47 & 5.42 & $0.045^{* *}$ \\
\hline Agreeableness & 39.97 & 5.17 & 38.56 & 5.04 & $0.007^{* *}$ \\
\hline Conscientiousness & 43.56 & 4.93 & 44.46 & 5.87 & $0.005^{* *}$ \\
\hline \multicolumn{6}{|c|}{ Diabetes Self-Care Activities } \\
\hline General diet & 4.40 & 2.00 & 2.61 & 1.844 & $0.0001^{* *}$ \\
\hline Vegetable and Fruits Diet & 5.05 & 1.78 & 3.98 & 1.932 & $0.0001 * *$ \\
\hline Red meat and Fats Diet & 1.46 & 1.38 & 1.82 & 1.756 & 0.71 \\
\hline Exercise & 4.29 & 2.46 & 1.74 & 2.290 & 0.0001 ** \\
\hline \multicolumn{6}{|c|}{ Physiological Measures of Blood Glucose Level } \\
\hline Glycosylated Haemoglobin $\left(\mathrm{HbA}_{1} \mathrm{C} \%\right)$ & 8.21 & 2.21 & 8.90 & 1.97 & 0.06 \\
\hline Fasting Blood Glucose level (in mg/dl) & 142.21 & 65.82 & 180.25 & 90.36 & $0.0001 * *$ \\
\hline Post-prandial measure (in $\mathrm{m} / \mathrm{dl}$ ) & 204.86 & 111.91 & 247.25 & 112.60 & $0.001^{* *}$ \\
\hline
\end{tabular}




\section{DISCUSSION}

The objective of the present study was to explore the differential personality profiles of patients with diabetes mellitus. In their national recommendations for psychosocial management of diabetes in India, Kalra and others [26] highlight the need to study the impact of psychological variables in managing diabetes. An individual performs much of the self-care behaviours and is at the core in the management of the illness. Hence, addressing personal, psychological variables that impact diabetes management can help target individual concerns in dealing with the illness. In the present study NEO-FFI- 3 model of personality [27] was utilised. Traits are relatively stable enduring, facets of human behaviour. Health behaviours are governed by same principles as other behaviours that are subject to self-regulation [28-29]. Hence, understanding the profiles of healthful, desirable behaviours with respect to personality variables can provide an impetus for promoting health behaviours in diabetes management. The present study strives to provide an empirical and theoretical understanding to the contribution of personality traits in diabetes management.

The relationship between personality traits with respect to self-care behaviours is not consistent in literature [18]. While, some studies have established poor self-care behaviours with negative temperaments [8] others have established a beneficial role [14]. On the basis of previous research, the domains of Neuroticism and Conscientiousness have been consistently implicated in much of the diabetes self-care behaviours. Simple correlational analyses reveal the significant negative impact of the domain of Neuroticism and the significant positive impact of the domain of Extraversion, Openness to Experience and Conscientiousness on different diabetes self-care behaviours. These findings are somewhat consistent with extant literature which mostly point to the negative impact of Neuroticism on self-care behaviours [8]. However, no significant differences in personality profiles of patients with respect to their type of diabetes could be established. Patients of the two groups also do not differ much with respect to the NEO-FFI-3 personality profiles. To the best knowledge of the authors, there are no Indian studies reported yet that compare the personality profiles of patients of Type- 1 and Type- 2 diabetes mellitus.

The Neuroticism domain of NEO-FFI-3 assesses aspects of negative affect, such as feelings of hostility, guilt, fear, anger, sadness, disgust and embarrassment. Individuals who score high on this domain are more prone to experience anxiety, anger in response to situations and stimuli as compared to those who score low in it. In such situations it is quite plausible for high scoring individuals to find it difficult to adapt to challenges which probably would be easy for others to cope with [11]. The rigours of health maintenance in living with diabetes could be perceived as being difficult and challenging. Neuroticism could have indirect effects on maintaining self-care behaviours. In present study, the domain of Neuroticism along with the domain of Conscientiousness accounted for $1.9 \%$ in predicting the self-care behaviour of exercise. Patients prone to emotional instability may get frustrated easily and hence find it difficult to persevere to a daily plan of physical exercise. It may be difficult for participants to perform physical exercise on a daily level when individuals have not always had a physically very active lifestyle. They may give in to rumination on the displeasure of the act itself and hence, find it difficult to adapt to this daily self-care behaviour. It could be the distress associated with living with daily regulations - the hallmark of diabetes management feels burdensome to such individuals.

The domain of Extraversion is considered to be closely associated with positive emotionality or positive affect [30-31]. Individuals who score high on this domain are considered to be high on qualities of - being assertive, active, talkative, social and cheerful while individuals who score low on this domain are more likely to be quiet, reserved, withdrawn and submissive [11]. People scoring high on this domain are more likely to experience happiness and subjective and existential well-being than those prone to introversion. This domain has rarely been found to be related to any consequential outcome, such as longevity, marital stability or occupational success [32]. However, in present study, higher Extraversion has been found to be predict $4.4 \%$ of the self-care behaviour - following recommended diet of fruits and vegetables. In the Summary of Diabetes Self-Care Activities (SDSCA), this particular self-care behaviour concerns with consuming the recommended portion of green vegetables and fruits in a week.

In diabetes management one of the critical components of self-care has to do with maintaining the appropriate recommended diet. The intake of fruits and vegetables is of importance here as a person with 
diabetes has to be mindful of the intake and portions of certain fruits and vegetables allowed for them. Extraverts are persons who are talkative, and are likely to ask questions more. True to these characteristics, extraverts are more likely to engage active coping skills such as problem - solving than disengagement or avoidance [33]. This could explain how certain levels of extraversion may be beneficial in adhering to this particular self-care behaviour.

Openness to Experience is a domain of the five-factor theory of personality, whose contribution in health behaviour per se has been quite inconsistent [34]. This particular domain can be considered as being very direct and of elemental sort, a literal opening of one's eyes and ears to the world around one [11]. High score on this domain indicate being curious, willingness to entertain novel ideas, unconventional values and the tendency to experience both positive and negative emotions more keenly than closed individuals. So, individuals scoring high on this domain tend to seek activities which may bring meaning and higher purposes to them. They are likely to seek out changes to their routine as compared to low scorers on this domain, who prefer sameness and predictability to their routine. In present study, this domain did not predict any self-care behavior, but significant association was established with self-care behaviors of following the recommended diet of fruits and vegetables and performing exercise behaviour. Similarly, the domain of Agreeableness, taps in to characteristics such as being sympathetic to others, altruistic, eager to help others and a belief in others helpful nature. It can be explained as the tendency to be tolerant and accepting rather than being cynical and hostile. However, there is a link between high scores on this domain with poor glycaemic control through way of self-care behaviours [14]. Diabetes management may require some amount of self-centredness and people who tend to be focused more on others needs may neglect their own self-care. In the present study, no noteworthy significant association was established between these domains with any particular self-care behaviours.

Conscientiousness is the domain concerned with aspects of what is known as character [11]. It concerns with the ability/inability to control impulses which includes active process of planning, organising, and carrying out tasks. Individuals who score high on this domain tend to be purposeful, strong-willed, determined and achievement oriented. The domain has been positively linked with longevity and a number of health behaviours over a period of time $[32,35]$. In the present study, this domain predicted around $2.2 \%$ of the self-care behaviour of following a general diet, and $6 \%$ of performing exercise behaviour. The importance of these personality traits in the performance of self-care behaviours is in being scrupulous and reliable. In the Summary of Diabetes Self-Care Activities (SDSCA), the self-care behaviour of following a general diet, concerns with following a healthful eating plan and the number of times in a week such a diet plan was followed by the patient. The self-care activity of performing exercise behaviours, concerns with performing physical activity a minimum of 30 minutes in the last seven days and in performing specific exercise sessions. From findings it can be observed that high scorers are individuals who possess traits such as being deliberate in actions, are dutiful and achievement striving, are more likely to accomplish the regular tasks of following a generally healthful eating plan and following the recommendations of being physically active in some form or another. The positive and very strong impact of Conscientiousness in different health behaviours' is a well-established one [36].

There exists a lot of variability in performance of self-care activities within the Indian diabetes patient population. The most commonly reported adhered self-activity was following medication [37-42], while, poor adherence has been cited for following diet and exercise regimen [41, 43-44]. A number of extraneous factors could account for differences in self-care activities. These contributing factors could be as varied as the linguistic and cultural landscape of India. The predictive capacity of personality traits in explaining health behaviours then needs to consider these other variables. One such variable is the socio-economic status (SES) of the participant [32].

The present study is a cross- sectional design. In any given day, a variety of patients make their way to an Indian tertiary hospital set-up such as the one in the study. The demographic backgrounds and socioeconomic profile of the patients is varied. Extant literature has established the beneficial role of the observed personality domains in different health behaviours [36]. In any attempt to understand choices of health behaviours of patients, it is necessary to acknowledge the impact that resource-limited set-ups within our state has on factors of clinical progression, treatment and outcome of any disease management [27]. Any process of classification is expensive in terms of resources and time. Classification by means of 
multivariate statistics such as cluster analysis can help in organising and understanding information based on certain features of similarity with respect to variables of interest [22]. In the present study, combining the five personality domains, two distinct clusters have been obtained. The two obtained clusters were found to be statistically significant with respect to four domains of the NEO-FFI-3 module - Extraversion, Openness to Experience, Agreeableness and Conscientiousness. Further, the two clusters are also statistically comparable in terms of self-care behaviours' and physiologic measures of glycaemic control.

The two groups of participants yielded, differ on four of the theoretically distinct personality domains. An exploration between the personality profiles, self-care behaviours' and measures of glycaemic control indicate that participants who score high on aspects of Extraversion, Openness to Experience, Agreeableness and Conscientiousness demonstrate more self-care behaviours of following general diet, following recommended diet of fruits and vegetables and performing exercise behaviour. Further, this set of participants, who demonstrate better self-care behaviours are also likely to show better blood glucose control. This classification of patients based on their personality profiles can help in understanding the performance of self-care behaviours.

The present study findings and interpretations are tentative and should be treated as such given the exploratory nature of the study. Three critical self-care behaviours pertaining to diet and exercise are implicated with respect to four domains of the five-factor model of personality. To the best knowledge of the authors there have been no known attempts to classify patients of diabetes on the basis of an established theoretical context of personality. The present study may be considered as extending beyond the extant studies on Indian patients of diabetes in studying personality traits on self-care behaviours [13] and comparison of the personality profiles against other groups of participants [21]. There exists scope for studying profiles in a longitudinal assessment of profiles of patients when it is set against the backdrop of a particular theoretical orientation. It provides a framework to compare with, to work with.

\section{Implications}

Understanding the particular traits to target to help bring about behavioural change is of importance. Personality traits can translate in to adoption of healthy/unhealthy behaviours [32]. In clustering personality domains - outcomes showed to be independent of factors such as age of patients and duration of illness - an exploration not undertaken previously. The findings indicate that personality profiles and its consecutive mapping on self-care behaviours can be one of the main indicators for subsequent health behaviour choices. Second, understanding the level of diabetes self-care, which is tapped by the Summary of Diabetes Self-Care Activities Measure (SDSCA) within the patient population can be an initial step in understanding the profile of self-care behaviours in patients. Foot care and smoking behaviour were ill represented in the study. This is indicative of lack of knowledge and subsequent translation in behaviours on part of the participants. This has implications for development of training and intervention programs.

In studying associations between personality traits and different self-care behaviours, it may not elucidate the process of how personality mediates health behaviour. But it can provide an impetus to understand the trait profile of patients with respect to concerned behaviours. Personality traits can help us identify individuals liable to better physical health. One of the mechanism through which it impacts health is through the choices of healthy and unhealthy behaviours [45]. The choices an individual makes in their daily life can determine their likelihood in adoption and maintenance of health behaviours. This has implications for health care providers in understanding personality profiles of varied patients. The results have deduced two personality profiles to target with respect to self-care behaviours. Overall it adds to the existing knowledge of how certain personality traits combine with self-care behaviours. This classification can help target at risk individuals. These patients may be at a higher risk of poorer psychological and physical health outcomes.

\section{Limitations of the study}

The current study is not without its limitations. First, the cross-sectional design of the study prevents understanding self-care behaviours in specific age segments of participants. Second, extant knowledge of self-care behaviours needs to be considered in participants. Lack of translation of knowledge in behaviour could be that knowledge of the particular self-care behaviour is not present in the first place. Third, in 
determining a more clear and detailed psychological causal profile of self-care behaviours, personal variables such as a patient's level of self-efficacy, patient's readiness need to be considered. This would allow for a detailed psychological profile mapping of patients and has implications in providing psychological care of patients.

\section{REFERENCES}

1. Booth- Kewley S, Vickers RR. Associations between major domains of personality and health behavior. J Personality 1994;62(3):281-98.

2. Friedman HS. Long- term relations of personality and health: Dynamisms, mechanisms, tropisms. J Personality 2000;68(6):1089-107.

3. Friedman HS. The multiple linkages of personality and disease. Brain Behav Immun 2008;22(5):668-75.

4. Tandon N, Raizada N. The burden of Diabetes in India, Sep 3, 2014. Diapedia derived from https://www.diapedia.org/introduction-to-diabetes-mellitus/1105045828/the-burden-of-diabetes-in-india

5. Sabaté E. Adherence to long-term therapies: evidence for action. World Health Organization: Geneva ; 2003.

6. Hagger-Johnson E, Whiteman MC. Conscientiousness facets and health behaviors: A latent variable modeling approach. Personal Individ Diff 2008;43:1235-45.

7. Goodwin RD, Friedman HS. Health status and the five-factor personality traits in a nationally representative sample. J Health Psychol 2006;11(5):643-54.

8. Axelsson M, Brink E, Lundgren J, Lötvall J. The influence of personality traits on reported adherence to medication in individuals with chronic disease: an epidemiological study in West Sweden. PLos One 2011;6(3):e18241.

9. Matthews G, Deary IJ, Whiteman MC. Personality traits. Cambridge University Press: Cambridge, UK; 2003.

10. McCrae RR, John OP. An introduction to the five- factor model and its applications. J Personality 1992;60(2):175-215.

11. McCrae RR, Costa Jr PT. A five-factor theory of personality. Handbook of personality: Theory and Research 1999;2:139-53.

12. Shamsi A, Khodaifar F, Arzaghi SM, Sarvghadi F, Ghazi A. Is there any relationship between medication compliance and affective temperaments in patients with type 2 diabetes?. J Diab Metab Disord 2014;13(1):96-100.

13. Dhurandher D, Shrivastav P. Diabetes management: A study in relation to personality, self efficacy and gender. International Journal of Current Research 2013;7(9):20726-9.

14. Lane JD, McCaskill CC, Williams PG, Parekh PI, Feinglos MN, Surwit RS. Personality correlates of glycemic control in type 2 diabetes. Diabetes Care 2000;23(9):1321-5.

15. Szymborska-Kajanek A, Strojek K. Hypoglycaemic treatment in type 2 diabetic patients after myocardial infarction. Diabet Res Clin Pract 2006;74(2):S30-2.

16. Williams PG, Colder CR, Lane JD, McCaskill CC, Feinglos MN, Surwit RS. Examination of the neuroticism-symptom reporting relationship in individuals with type 2 diabetes. Personal Soc Psychol Bull 2002;28(8):1015-25.

17. Jokela M, Elovainio M, Nyberg ST, Tabák AG, Hintsa T, Batty GD, Kivimäki M. Personality and risk of diabetes in adults: Pooled analysis of 5 cohort studies. Health Psychol 2014;33(12):1618-21.

18. Seides R. Do personality traits predict compliance with type 2 diabetes regimens?. Doctoral dissertation, Teachers College, Columbia University; 2012.

19. Wheeler K, Wagaman A, McCord D. Personality traits as predictors of adherence in adolescents with type I diabetes. J Child Adolesc Psych Nurs 2012;25(2):66-74.

20. Noroozi A, Tahmasebi R, Shaybani B. Relationship between personality trait and self-management in diabetic patients referred to Bushehr medical centers in 2012-13. ISMJ 2014;16(6):436-46.

21. Jyotsana S. Personality and stress of NIDDM patients - a comparative study. Indian J Psychol Sci 2011; $2(2): 38-50$.

22. Clatworthy J, Buick D, Hankins M, Weinman J, Horne R. The use and reporting of cluster analysis in health psychology: A review. Br J Health Psychol 2005;10(3):329-58.

23. Amutha A, Kalpana T, Mohan V. Childhood and Adolescent Onset Type 1 Diabetes in India. MGM J Med Sci 2014;1(1):46-53.

24. Kumar BR, Dudala SR, Rao AR. Kuppuswamy's socio-economic status scale-a revision of economic parameter for 2012. Int J Res Dev Health 2013;1(1):2-4.

25. Toobert DJ, Hampson SE, Glasgow RE. The summary of diabetes self-care activities measure: results from 7 studies and a revised scale. Diabet Care 2000;23(7):943-50.

26. Borgen FH, Barnett DC. Applying cluster analysis in counseling psychology research. J Couns Psychol 1987;34(4):456-76. 
27. Kalra S, Sridhar GR, Balhara YP, Sahay RK, Bantwal G, Baruah MP, John M, Unnikrishnan AG, Madhu K, Verma K, Sreedevi A. National recommendations: Psychosocial management of diabetes in India. Indian J Endocrinol Metab 2013;17(3):376-95.

28. Loehlin JC, McCrae RR, Costa Jr PT, John OP. Heritabilities of common and measure-specific components of the Big Five personality factors. J Res Personal 1998;32(4):431-53.

29. de Ridder D, De Wit J. Self-regulation in health behavior. John Wiley \& Sons: New York; 2006.

30. Hampson SE. Personality processes: Mechanisms by which personality traits get outside the skin. Ann Rev Psychol 2012;63:315-39.

31. John OP, Srivastava S. The Big Five trait taxonomy: History, measurement, and theoretical perspectives. Handbook of personality: Theory and research. 1999;2(1999):102-38.

32. Roberts BW, Kuncel NR, Shiner R, Caspi A, Goldberg LR. The power of personality: The comparative validity of personality traits, socioeconomic status, and cognitive ability for predicting important life outcomes. Persp Psychol Sci 2007;2(4):313-45.

33. Carver CS, Connor-Smith J. Personality and coping. Ann Rev Psychol 2010;61:679-704.

34. Eldesouky L. Openness to experience and health: A review of the literature. Yale Rev Undergrad Res Psychol 2002;5:24-42.

35. Kern ML, Friedman HS. Do conscientious individuals live longer? A quantitative review. Health Psychol 2008;27(5):505-20.

36. Friedman HS, Kern ML, Hampson SE, Duckworth AL. A new life-span approach to conscientiousness and health: Combining the pieces of the causal puzzle. Dev Psychol 2014;50(5):1377-89.

37. Suguna A, Magal AS, Stany A, Sulekha T, Prethesh K. Evaluation of self-care practices among diabetic patients in a rural area of Bangalore district, India. International Journal of Current Research and Academic Review 2015;3(6):415-22.

38. Padma K, Bele SD, Bodhare TN, Valsangkar S. Evaluation of knowledge and self-care practices in diabetic patients and their role in disease management. Natl J Commun Med 2012;3(1):3-6.

39. Arulmozhi S, Mahalakshmy T. Self-Care and Medication Adherence among Type 2 Diabetics in Puducherry, Southern India: A Hospital Based Study. J Clin Diag Res 2014;8(4):UC01-03.

40. Sadikot SM, Nigam A, Das S, Bajaj S, Zargar AH, Prasannakumar KM, Sosale A, Munichoodappa C, Seshiah V, Singh SK, Jamal A. The burden of diabetes and impaired glucose tolerance in India using the WHO 1999 criteria: prevalence of diabetes in India study (PODIS). Diabet Res Clin Pract 2004;66(3):301-7.

41. Gopichandran V, Lyndon S, Angel MK, Manayalil BP, Blessy KR, Alex RG, Kumaran V, Balraj V. Diabetes Self-care activities: A community based survey in urban southern India. Natl Med J India 2014;25(1):14-7.

42. Mukhopadhyay P, Paul B, Das D, Sengupta N, Majumder R. Perceptions and practices of type 2 diabetics: A cross-sectional study in a tertiary care hospital in Kolkata. Int J Diabetes Dev Countries 2010;30(3):143-8.

43. Rajasekharan D, Kulkarni V, Unnikrishnan B, Kumar N, Holla R, Thapar R. Self care activities among patients with diabetes attending a tertiary care hospital in Mangalore Karnataka, India. Ann Med Health Sci Res 2015;5(1):59-64.

44. Mumu SJ, Saleh F, Ara F, Afnan F, Ali L. Non-adherence to life-style modification and its factors among type 2 diabetic patients. Indian J Pub Health 2014;58(1):40-4.

45. Hill PL, Roberts BW. The role of adherence in the relationship between conscientiousness and perceived health. Health Psychol 2011;30(6):797-803.

$* * * * * * * * * * * * * * * * * * * * * * *$

$$
\begin{gathered}
\text { Acknowledgements - Nil } \\
\text { Conflict of Interest - Nil } \\
\text { Funding - Nil }
\end{gathered}
$$

